\title{
Effect of Water-Decked Blasting on Rock Fragmentation Energy
}

\author{
Wenjun Xia $\mathbb{D}^{1,2}$, Wenbo Lu $\mathbb{D}^{1,2}$ Ruize Li, ${ }^{1,2}$ Ming Chen, ${ }^{1,2}$ and Zhen Lei ${ }^{3}$ \\ ${ }^{1}$ State Key Laboratory of Water Resources and Hydropower Engineering Science, Wuhan University, Wuhan 430072, China \\ ${ }^{2}$ College of Water Resource and Hydropower, Wuhan University, Wuhan 430072, China \\ ${ }^{3}$ China No. 8 Water Conservancy and Water Power Engineering Bureau, Changsha 410004, China
}

Correspondence should be addressed to Wenbo Lu; wblu@whu.edu.cn

Received 15 November 2019; Revised 12 May 2020; Accepted 26 May 2020; Published 25 June 2020

Academic Editor: Marco Alfano

Copyright (c) 2020 Wenjun Xia et al. This is an open access article distributed under the Creative Commons Attribution License, which permits unrestricted use, distribution, and reproduction in any medium, provided the original work is properly cited.

\begin{abstract}
Fragmentation energy ratio is an important index to evaluate whether an explosive is used efficiently. This paper discusses the effect of water-decked blasting on fragmentation energy based on theory and numerical simulation, and three blasting tests were performed to measure the actual fragmentation energy at a granite-based field. Results show that at the same charge amount, the maximum borehole pressure of water-decked blasting is much greater than that of normal blasting in theory, which facilitates rock breaking. In numerical simulation, water-decked blasting is more beneficial to the transmission of explosive energy; therefore, the damage distribution is more uniform and the damage level is higher. The specific surface area and fragment size distribution were obtained by three-dimensional laser scanning and image analysis in field tests; therefore, the fragmentation energy could be measured, which showed that the fragmentation energy could be increased by $10 \%$ in water-decked blasting. In addition, waterdecked blasting can reduce fly rocks and ensure the safety of rock blasting.
\end{abstract}

\section{Introduction}

Blasting is the most popular method in rock breaking, which is widely used in mining, foundation excavation, tunnel excavation, and so on [1]. However, as explosion is a violent chemical reaction, the explosive energy is difficult to control and utilize. Only a small portion is used for rock breaking, while the remaining is dissipated and not used [2]. The efficiency of rock breaking significantly affects downstream production processes, such as shoveling, transportation, and grinding [3]. Improving the ratio of fragmentation energy has become the main goal when establishing blasting plans.

The main function of fragmentation energy is to drive the formation and propagation of new cracks during rock blasting [4]. A portion of the energy primarily creates new cracks that are hidden in the rock fragments, which is called microfragmentation energy. As it is difficult to observe these cracks directly, researchers have used electron microscopy to compare the total area of microcracks of rock fragments collected from the same area before and after blasting; they discovered that the ratio of microfragmentation energy was approximately $11 \%[5,6]$. The fracture of intact rock mass is the main goal of bench blasting; therefore, macrofragmentation energy is the most typically used index to evaluate the utilization efficiency of explosive energy, which depends on the specific surface energy and the new surface area of rock fragments [7]. The surface area of fragments is difficult to measure; currently, it is generally assumed that the fragments are spherical or cubic particles [8], and the fragment size distribution (FSD) is obtained by a prediction algorithm [9] or photogrammetry [10]; then, the surface area can be calculated. Compared with the shape assumption, the specific surface area can better reflect the relationship between sieve size and rock fragment shape as well as yield more accurate measurements of macrofragmentation energy $[11,12]$.

Changing charge patterns is sometimes useful to improve blasting effect and utilization efficiency of explosive energy $[13,14]$, and water is a typically used medium. Compared with air, water has a higher density, and even in extremely high pressures, the compression of water is much smaller than that of air [15]. Therefore, the impact pressure of the detonation wave is higher, and the action time of the explosion gas remains longer in water-decked blasting, 
which is conducive to rock breaking [16]. Because the immersion of water will affect the performance of the explosive, a water bag is used to separate cartridges axially. By placing the water bag at the bottom of a borehole, rock fragmentation can be strengthened, which facilitates the elimination of the residual root of blasting and reduction of blasting vibrations [17].

Herein, the maximum borehole pressure in normal and axial water-decked blasting is analyzed theoretically. With numerical simulation technology, the blasting damage and blasting energy distributions of the two charge patterns are compared. Three blasting tests were performed at a granitebased field, and the fragmentation energy of each bench blasting was calculated. This study facilitates the optimization of the blasting plan and utilization efficiency improvement of explosive energy.

\section{Mechanism of Water-Decked Blasting}

2.1. Energy Components in Rock Blasting. The interaction between an explosive and a rock mass is complicated $[18,19]$. First, the rock mass around a borehole is crushed by shock waves. Subsequently, the shock wave is transformed into a stress wave that propagates outward in the rock mass. Microcracks will be activated and propagated; some accumulate to form macrocracks, causing intact rock mass to become small fragments. With the attenuation of stress waves, microcracks stop propagating and elastic deformation primarily occurs in rock mass [20]. Meanwhile, rock fragments will be thrown forward under the action of an explosion gas to form a muck pile [21]. In addition, air blast and gas enthalpy will consume energy in blasting. Therefore, the explosive energy during blasting can be categorized into macrofragmentation energy, microfragmentation energy, seismic energy, kinetic energy, and others, as shown in Figure 1.

The propagation of cracks driven by stress waves consumes a large amount of explosive energy. Assuming that the cracks are spherical, the energy consumed is expressed by [22]

$$
E_{C}=4 \pi r^{2} N G_{F}
$$

where $r$ is the average radius of microcracks, $N$ is the number of microcracks, and $G_{F}$ is the specific fracture energy to form a unit free surface area, which is obtained experimentally [23]. As the propagation of cracks can be manifested as the weakening of the mechanical properties of rock mass, (1) can be written as follows [24]:

$$
E_{C}=\int_{0}^{t} K(1-D) \dot{\varepsilon}_{0}^{2} t \mathrm{~d} t
$$

where $K$ is the bulk modulus, $D$ is the damage variable, and $\dot{\varepsilon}_{0}$ is the strain rate. Microcracks are rarely involved because they are difficult to be observed directly, so the existing study primarily focuses on macrocracks. Generally, a larger damage variable $D$ implies a greater crack density and a smaller size of rock fragments [25]; therefore, the

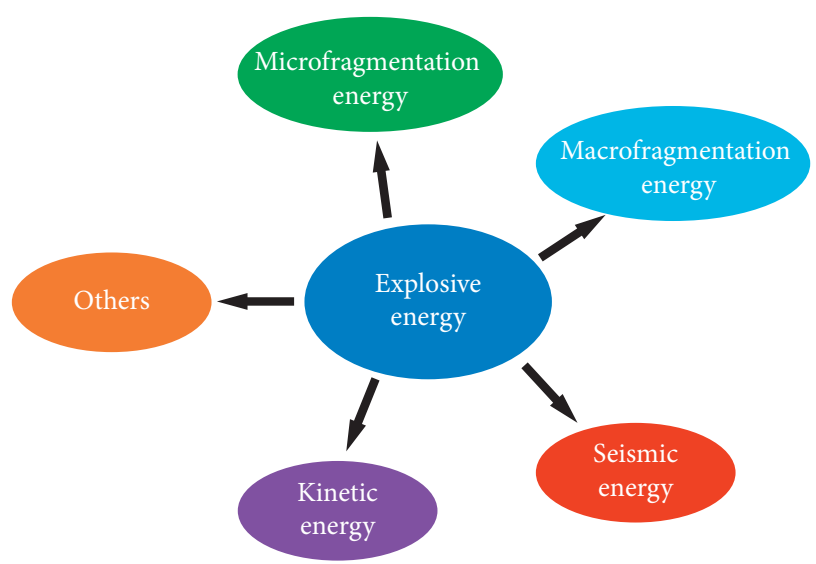

FIGURE 1: Energy components of explosive in blasting.

macrofragmentation energy can indicate the utilization efficiency of explosive energy in engineering [8]:

$$
E_{F}=G_{F} \cdot\left(\int_{x_{k}^{I}}^{x_{k}^{S}} \rho V(x) S_{V}(x) \mathrm{d} x-A_{I S}\right),
$$

where $x_{k}^{S}$ and $x_{k}^{I}$ are the upper and lower size limits of rock fragments, respectively, $V$ is the total volume of the rock fragments, $A_{I S}$ is the original surface area of rock mass, and $S_{V}$ is the specific surface area, which is expressed as follows [12]:

$$
S_{V}=\frac{S}{V \rho}
$$

where $\rho$ is the density of rock mass and $S$ is the surface area of rock fragments. For large rock fragments, the geometric information can be obtained by three-dimensional (3D) laser scanning [26], whereas for small rock fragments, owing to the limitation of scanning, image analysis technology can be used to achieve higher accuracy. At present, small rock fragments are generally regarded as cubic or spherical particles [8], while elliptical shape hypothesis can describe the shape of fragments better; combined with the two-dimensional (2D) projection image, its specific surface area can be expressed as follows [27]:

$$
S_{V}=\frac{\alpha_{1} 4 \pi r_{1}^{2}}{(4 / 3) \pi r_{1}^{3} \rho}=\frac{3 \alpha_{1}}{r_{1} \rho},
$$

where $\alpha_{1}$ is the equivalent ellipse correction factor. The function of an ellipsoid can be written as follows:

$$
\frac{x^{2}+y^{2}}{a^{2}}+\frac{z^{2}}{c^{2}}=1,
$$

where $a$ is the long axis and $c$ is the short axis. When $a<c$, the ellipsoid is rotated around the long axis, and the equivalent ellipse correction factor $\alpha_{1}$ is expressed as

$$
\alpha_{1}=\frac{2 \pi a c^{2} \sqrt{\left(1 / c^{2}-a^{2}\right)} \cdot \arcsin \left(\sqrt{c^{2}-a^{2}} / c\right)+2 \pi a^{2}}{\left(4 \pi a^{2} c / 3\right)} \cdot \frac{r_{1}}{3},
$$

where $r_{1}$ is the equivalent spherical radius of the ellipsoid volume and $r_{1}=\sqrt[3]{a^{2} c}$. When $a>c$, the ellipsoid is rotated 
around the short axis, and the equivalent ellipse correction factor $\alpha_{1}$ is expressed as

$$
\alpha_{1}=\frac{2 \pi a^{2}+\left(2 \pi a c^{2} / \sqrt{a^{2}-c^{2}}\right) \cdot \ln \left(a+\sqrt{a^{2}-c^{2}} / c\right)}{\left(4 \pi a^{2} c / 3\right)} \cdot \frac{r_{1}}{3} .
$$

Assuming that the probability of these two conditions is $50 \%$ and combined with equations (5)-(8), the specific surface area of small rock fragments can be measured.

\subsection{Interaction between Explosive and Rock Mass in Water-} Decked Blasting. A cartridge is typically used in normal blasting. To ensure that cartridges can enter into the boreholes smoothly, the diameter of cartridges is slightly smaller than the diameter of boreholes, so the normal blasting is generally decoupled charge, whereas in axial water-decked blasting, the fully coupled charge should be used to ensure the consistency of the powder factor and stemming length, which will also affect the fragmentation energy in rock blasting. The two types of charge patterns are shown in Figure 2.

Because the diameter of cartridges is typically smaller than that of a borehole, a gap typically appears between the cartridge and the borehole wall in normal blasting; therefore, the maximum pressure in the borehole $P_{0}$ can be expressed as $[28]$

$$
P_{0}=\frac{\rho_{e} D^{2}}{2(\gamma+1)}\left(\frac{r_{c}}{r_{d}}\right)^{2 \gamma}
$$

where $\rho_{e}$ is the density of the explosive, $D$ is the detonation velocity of the explosive, $\gamma$ is an adiabatic expansion index $(\gamma=3.0), r_{c}$ is the radius of the cartridge, and $r_{d}$ is the radius of the borehole. In water-decked blasting, the water column will be compressed by explosion gas; therefore, the maximum borehole pressure after expansion $P_{b}$ is expressed as follows [29]:

$$
P_{b}=P_{0}\left(\frac{L_{C}}{L_{C}+h}\right)^{\gamma}
$$

where $L_{C}$ is the charge length and $h$ is the compressed length of the water column when the pressure reaches equilibrium in the borehole. $L_{W}$ represents the length of the water column, the ratio of charge length to the water column is $K_{C}=L_{C} / L_{W}$, and the ratio of charge length to the compressed length of the water column is $K_{h}=L_{h} / L_{W}$; therefore, (10) can be written as

$$
P_{b}=P_{0}\left(\frac{K_{C}}{K_{C}+K_{h}}\right)^{\gamma} .
$$

Meanwhile, according to hydrodynamic theory, when the water column is compressed, the water pressure will increase. When the pressure reaches equilibrium in the borehole, the water pressure is expressed as follows:

$$
P_{b}=E_{V} \ln \left(\frac{1}{1-K_{h}}\right),
$$

where $E_{V}$ is the bulk modulus of water. According to (11) and (12), the borehole pressure can be obtained in waterdecked blasting. Using the typical bench blasting as an example, as shown in Table 1 , emulsion explosive \#2 is considered as its density is $1200 \mathrm{~kg} / \mathrm{m}^{3}$ and detonation velocity is $4300 \mathrm{~m} / \mathrm{s}$. The maximum borehole pressure of the water-decked blasting is 1.79 times that of normal blasting. As the radius of cracked zone [30] is always positively correlated with the maximum borehole pressure during blasting, it implies the rock breaking can be improved significantly in water-decked blasting.

\section{Numerical Simulation of Normal Blasting and Water-Decked Blasting}

3.1. Numerical Model and Parameters. To reveal the effects of different charge patterns on the energy distribution of explosives, nonlinear dynamic finite element software AUTODYN was used to simulate multihole bench blasting in rock mass. As shown in Figure 3, the numerical model measured $11 \mathrm{~m} \times 13 \mathrm{~m} \times 4 \mathrm{~m}$, and 462000 elements were considered. The diameter of the borehole was $100 \mathrm{~mm}$, and the depth was $10.0 \mathrm{~m}$. The two sides of the model were symmetrical boundaries, and the top and bench faces were free surfaces. A fluid-solid coupling algorithm was adopted to simulate the interaction of different media during blasting. The initiation point was at the bottom of the borehole, and an $80 \mathrm{~mm}$ cartridge was used in normal charge blasting, whereas a $100 \mathrm{~mm}$ cartridge was used in waterdecked blasting to ensure the same charge amount in the borehole.

The Jones-Wilkins-Lee (JWL) equation of state is used to describe the relationship among the pressure, energy, and volume of a detonation product during an explosion. The pressure determined by the JWL equation of state is as follows [31]:

$$
P_{d}=A\left(1-\frac{\omega}{R_{1} V}\right) e^{-R_{1} V}+B\left(1-\frac{\omega}{R_{2} V}\right) e^{-R_{2} V}+\frac{\omega E_{0}}{V} \omega,
$$

where $A, B, R_{1}, R_{2}$, and $\omega$ are constants determined experimentally, $V$ is the relative volume, and $E_{0}$ is the initial internal energy. An emulsion was adopted in the numerical simulations. Table 2 shows the parameters of the JWL equation.

A rock was simulated using the RHT model, which considers the characteristics of strain hardening, strain rate sensitivity, and compression damage softening during rock failure [32]. Compression and tensile damages were contained to simulate brittle materials under impact loading, such as concrete and rocks; the rock mechanical parameters used in the numerical simulation are shown in Table 3.

3.2. Result Analysis. Damage indicates the density of microcracks; in general, the higher the damage level is, the higher the density of microcracks is and the smaller the rock fragments after blasting are. Figure 4 shows the distribution of blasting damage of two different charge patterns at two 


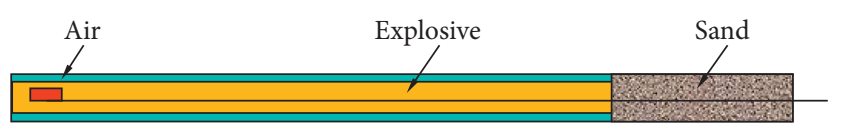

(a)

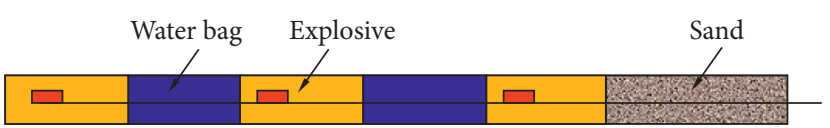

(b)

Figure 2: Two types of charge patterns of blasting. (a) Normal blasting. (b) Water-decked blasting.

TABLE 1: Maximum borehole pressure of two types of charge patterns in theory.

\begin{tabular}{lccccccc}
\hline Type & $r_{c}(\mathrm{~mm})$ & $r_{d}(\mathrm{~mm})$ & $L_{W}(\mathrm{~m})$ & $L_{C}(\mathrm{~m})$ & $E_{V}(\mathrm{GPa})$ & $Q(\mathrm{~kg})$ & $P_{b}(\mathrm{MPa})$ \\
\hline Normal blasting & 40 & 50 & 0 & 8 & 2.18 & 46.0 & 727 \\
Water-decked blasting & 50 & 50 & 3.12 & 4.88 & 2.18 & 46.0 & 1299 \\
\hline
\end{tabular}

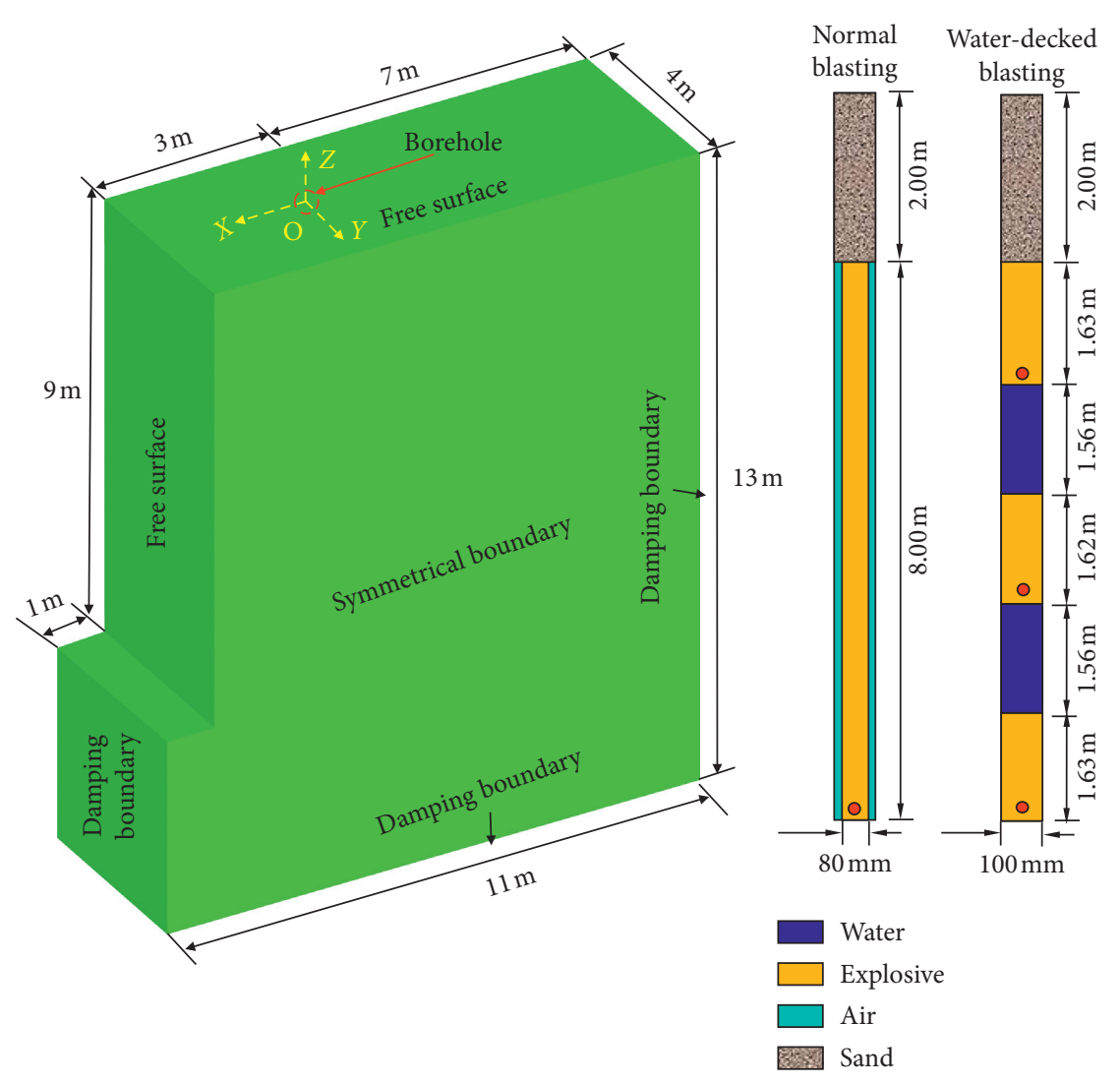

Figure 3: Numerical model of different charge patterns.

slice planes. At the slice plane XOZ, the damage distribution is more uniform and the damage level is higher in waterdecked blasting. Meanwhile, the radius of the damage zone is greater in water-decked blasting, which will be beneficial to rock fragmentation when the rear row boreholes are detonated. At the slice plane YOZ, it is clear that the waterdecked blasting will strengthen the damage of the rock mass between the boreholes, which facilitates the elimination of the residual root of blasting and the reduction of boulders because of the stemming. Based on the damage distribution, water-decked blasting is clearly beneficial to rock fragmentation.
During the rock blasting, energy exchange occurs between the rock and the explosion products continuously, which is accompanied by energy dissipation. In the continuum model, neglecting the heat exchange between different materials, the total energy $W_{R}$ absorbed by rock includes the elastic strain energy $W_{E}$, the plastic energy $W_{P}$, and the damage energy $W_{D}$, which can be written as

$$
W_{R}=W_{E}+W_{P}+W_{D} \text {. }
$$

According to the time history curve of materials in numerical simulation, the energy distributions of two types of charge patterns can be obtained, as shown in Figure 5. 
TABle 2: Parameters of JWL equation.

\begin{tabular}{lccccccc}
\hline $\begin{array}{l}\rho \\
\left(\mathrm{kg} / \mathrm{m}^{3}\right)\end{array}$ & $\begin{array}{c}\text { VOD } \\
(\mathrm{m} / \mathrm{s})\end{array}$ & $\begin{array}{c}A \\
(\mathrm{GPa})\end{array}$ & $B(\mathrm{GPa})$ & $R_{1}$ & $R_{2}$ & $\omega$ & $\begin{array}{c}E_{0} \\
(\mathrm{MJ} / \mathrm{kg})\end{array}$ \\
\hline 1200 & 4300 & 209.7 & 3.5 & 5.8 & 1.3 & 0.39 & 3.99 \\
\hline
\end{tabular}

TABLE 3: Parameters used in the RHT model for rock.

\begin{tabular}{lc}
\hline Parameters & Value \\
\hline Reference density $\left(\mathrm{g} / \mathrm{cm}^{3}\right)$ & 2.75 \\
Porous density $\left(\mathrm{g} / \mathrm{cm}^{3}\right)$ & 2.31 \\
Porous sound speed $(\mathrm{m} / \mathrm{s})$ & 2920 \\
Bulk modulus, $A_{1}(\mathrm{GPa})$ & 35.3 \\
Shear modulus, $G(\mathrm{GPa})$ & 16.7 \\
Compressive strength, $f_{c}(\mathrm{MPa})$ & 35.0 \\
Tensile strength, $f_{t} / f_{c}$ & 0.100 \\
Shear strength, $f_{s} / f_{c}$ & 0.180 \\
Intact failure surface constant, $A$ & 1.600 \\
Intact failure surface exponent, $N$ & 0.610 \\
Tensile/compressive meridian ratio, $Q$ & $6.805 \times 10^{-1}$ \\
Brittle to ductile transition, $B_{Q}$ & $1.050 \times 10^{-2}$ \\
Elastic strength/ $f_{t}$ & 0.700 \\
Elastic strength $/ f_{c}$ & 0.530 \\
Compressive strain rate exponent, $\alpha$ & $3.2 \times 10^{-2}$ \\
Compressive strain rate exponent, $\delta$ & $3.6 \times 10^{-2}$ \\
Damage constant, $D_{1}$ & 0.150 \\
Damage constant, $D_{2}$ & 1.000 \\
\hline
\end{tabular}

Figure 6 shows the energy distribution of two types of charge patterns; in water-decked blasting, the ratio of energy transmitted into the rock mass is larger, and the energy for rock damage is also larger, which increased by $15 \%$. Waterdecked blasting is conducive to the transmission of explosive energy and can improve the utilization efficiency of explosives.

\section{Field Tests for Fragmentation Energy}

4.1. Test Location and Main Parameters. The test site is located at the Nanshan District of Shenzhen city, China, and it is close to the Chiwan Mountain Park and Xinghai Avenue. A granite-based field was chosen for the blasting tests, and the main mechanical parameters of granite are shown in Table 4. Deep-hole millisecond bench blasting was adopted for rock excavation, and emulsion explosive \#2 was used primarily, whose density is $1200 \mathrm{~kg} / \mathrm{m}^{3}$, detonation velocity is $4300 \mathrm{~m} / \mathrm{s}$, and explosive heat is $3.991 \mathrm{MJ} / \mathrm{kg}$.

To study the effects of different charge patterns on the fragmentation energy in bench blasting, two normal blasting tests and one water-decked blasting test were performed; the main blasting parameters are the same, as shown in Table 5. Figure 7 shows the placement of the water bag in waterdecked blasting; the diameter of the water bag is $102 \mathrm{~mm}$, which is slightly smaller than the diameter of the borehole for placement, and the length of water bag is approximately $3.2 \mathrm{~m}$. The cartridges were scratched to fill the same amount of explosives in the water-decked blasting test, as shown in Figure 2. Two boreholes were detonated simultaneously; \#9 millisecond detonators were used for delay in the borehole, and \#3 millisecond detonators were used for the delay between segments.

\subsection{Analysis of Fragmentation Energy}

4.2.1. Specific Surface Area. Specific surface area is an important parameter to describe the relationship between sieve size and shape. For large rock fragments $(d>150 \mathrm{~mm}), 3 \mathrm{D}$ laser scanning was performed to obtain the coordinate information of the fragments' surface; subsequently, it was imported into software Scene and Geomagic Studio to create $3 \mathrm{D}$ models, and the specific surface area could be measured. To improve the efficiency of this test, 10-12 rock fragments of different sizes were arranged in a row and scanned simultaneously. A certain distance was reserved between each rock fragment to avoid mutual occlusion, and 5-6 test points from different angles were used for scanning in each test, so the coordinate information of rock fragments could be recorded completely for model creation, as shown in Figure 8.

For small rock fragments $(d<150 \mathrm{~mm})$, because the minimum spacing of the 3D laser scanning points was $5 \mathrm{~mm}$, only a few points on the surface of rock fragments could be recorded, which resulted in a large error. Based on stereology, a $2 \mathrm{D}$ planar projection was used to infer the $3 \mathrm{D}$ information of the rock fragments; subsequently, the specific surface area was obtained. The surface of the rock fragments was colored with black ink for a better contrast to facilitate the binarization of photographs, as shown in Figure 9. Image-Pro Plus software was used to obtain the geometric parameters of the rock fragment projection, considering the assumption that the small rock fragments were ellipsoid like; hence, the specific surface area could be measured.

A total of 1878 samples were analyzed in this test, and the size of each fragment was randomly distributed between $3 \mathrm{~mm}$ and $3000 \mathrm{~mm}$. Figure 10 shows the variation in the specific surface area with different particle sizes of granite in the field test. By regression analysis, it was clear that a good exponential relationship existed between the specific surface area and the particle size, and the correlation coefficient exceeded 0.92. Considering the number and representativeness of the samples, the relationship was considered valid in the entire size range.

4.2.2. Fragment Size Distribution. Fragment size distribution is an important index to evaluate the blasting effect. Currently, the Kuz-Ram model is generally used to predict size distribution in engineering [33]. It is simple and can predict with high accuracy, but many parameters are set based on experience; therefore, large errors may exist among different users and field conditions. With the development of computer technology, image analysis software was used to study the fragment size distribution, and 2D photo-based rock fragmentation measurement methods were most commonly used because of their convenience, while 3D rock fragmentation measurement methods with better accuracy have been gradually developed recently [34]. By capturing 


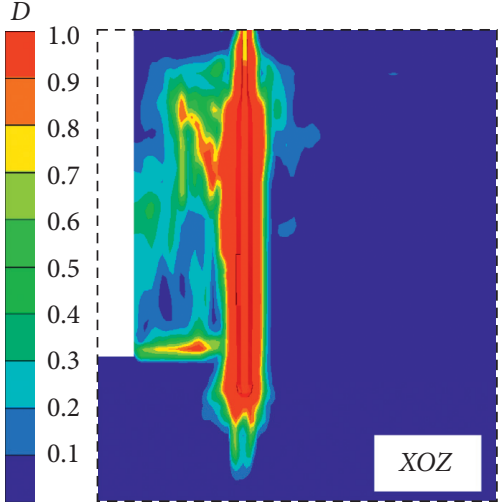

(a)

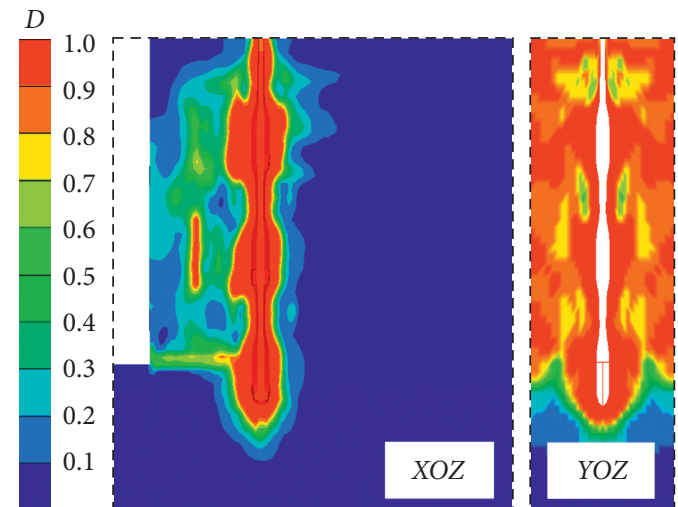

(b)

FIgURE 4: Blasting damage distribution under different charge patterns. (a) Normal blasting. (b) Water-decked blasting.

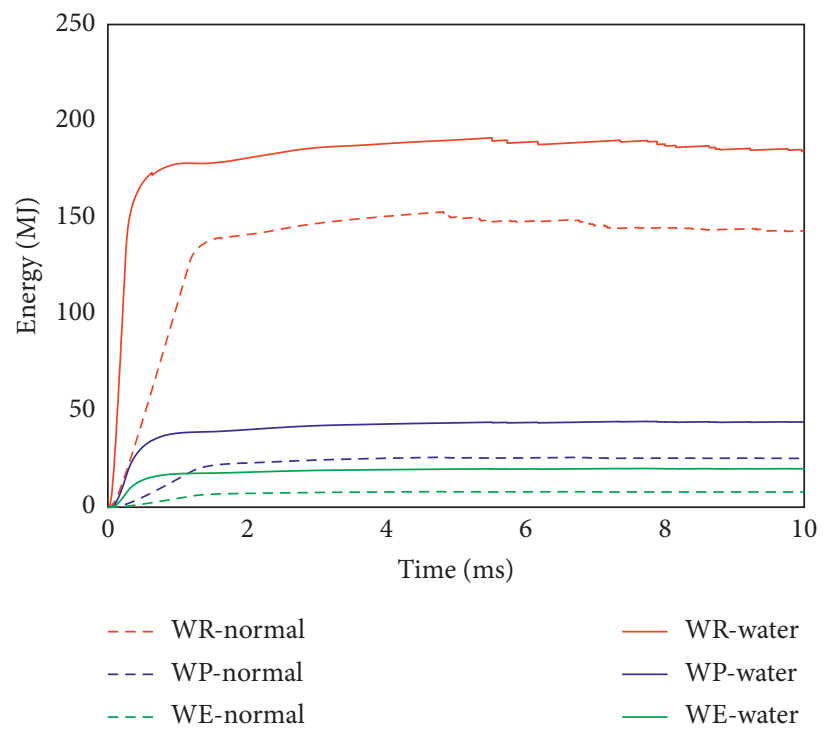

FIGURE 5: Time history curve of different energy components in rock mass.

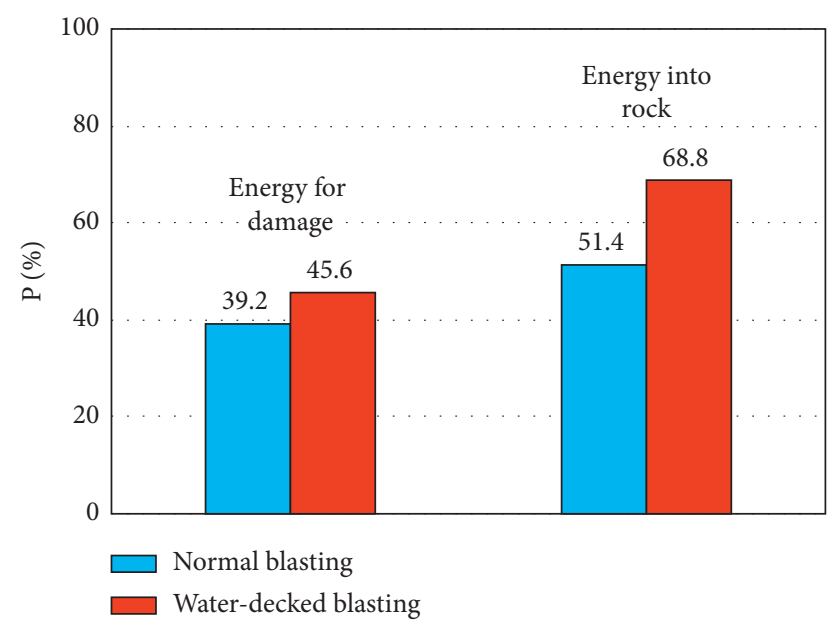

FIGURE 6: Energy distribution of two types of charge patterns.
TABLE 4: Main mechanical parameters of granite.

\begin{tabular}{lccccc}
\hline$\rho\left(\mathrm{kg} / \mathrm{m}^{3}\right)$ & $E(\mathrm{GPa})$ & $v$ & $\sigma_{c}(\mathrm{MPa})$ & $\sigma_{t}(\mathrm{MPa})$ & $G_{F}\left(\mathrm{~J} / \mathrm{m}^{2}\right)$ \\
\hline 2860 & 74 & 0.22 & 208 & 16 & 519.7 \\
\hline
\end{tabular}

sufficient representative photographs from the muck pile, image analysis software WipFrag can automatically identify the edges of rock fragments and generate a size distribution curve; Figure 11 shows how photographs are captured from a muck pile in this test and the recognition results of typical photographs.

Figure 12 shows the fragment size distribution and surface area in each size range (SA) of three blasting tests, where " $P(x)$ " is the cumulative size distribution of the fragments. In the normal blasting test, the medium fragment size was $344 \mathrm{~mm}$ and $351 \mathrm{~mm}$, while it was $322 \mathrm{~mm}$ in the water-decked blasting test, which indicated a clearer 
TABLE 5: Main parameters of blasting tests.

\begin{tabular}{lcccccccc}
\hline No. & Type & $N$ & $d_{b}(\mathrm{~mm})$ & $d_{c}(\mathrm{~mm})$ & $H(\mathrm{~m})$ & $B \times S(\mathrm{~m})$ & $Q(\mathrm{~kg})$ & $q\left(\mathrm{~kg} / \mathrm{m}^{3}\right)$ \\
\hline 1 & Normal blasting & & & & & & \\
2 & $\begin{array}{c}\text { Normal blasting } \\
3\end{array}$ & 22 & 115 & 90 & 12.0 & $4.0 \times 4.0$ & 63 & 0.35 \\
\hline
\end{tabular}

$N$ : number of boreholes; $d_{b}$ : diameter of borehole; $d_{c}$ : diameter of cartridge; $H$ : hole depth; $B$ : burdens; $S$ : space; $Q$ : charge weight in single hole; $q$ : powder factor.

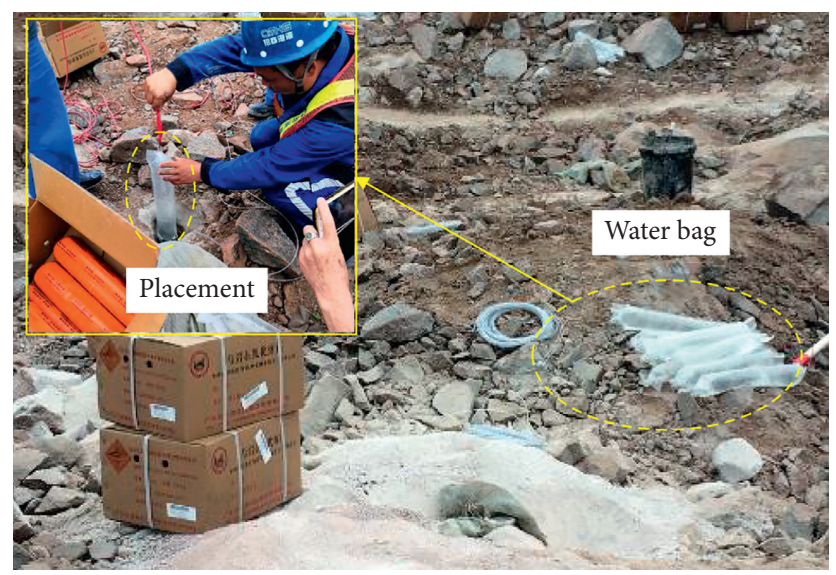

FIgURE 7: Placement of water bag in water-decked blasting.

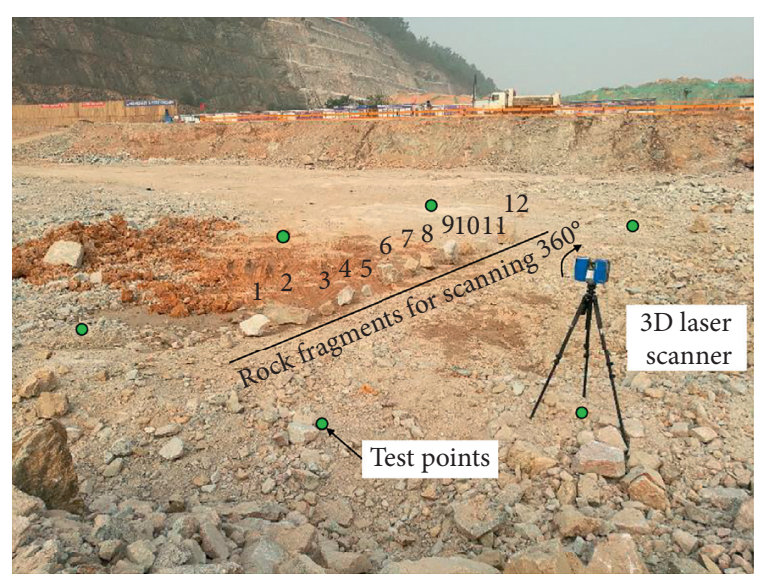

(a)

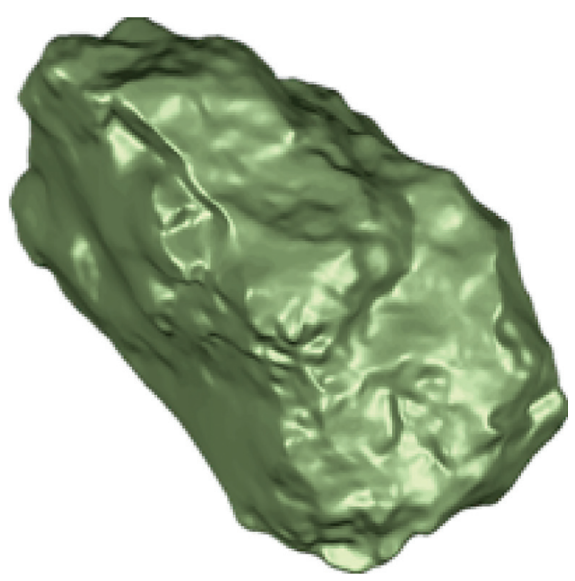

(b)

Figure 8: 3D laser scanning for large rock fragments. (a) Arrangement of scanning points. (b) 3D model of rock fragments.

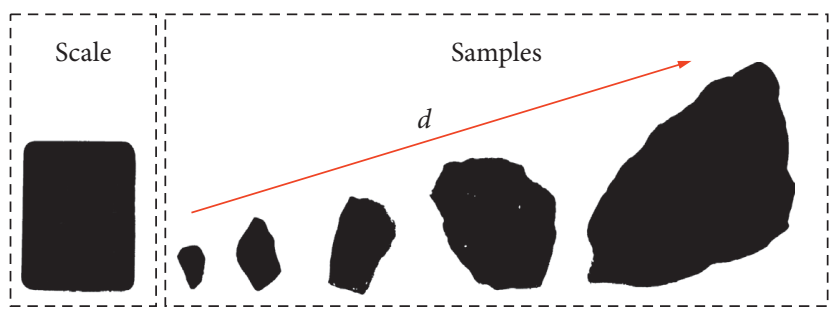

Figure 9: Binarization image of small rock fragments. 


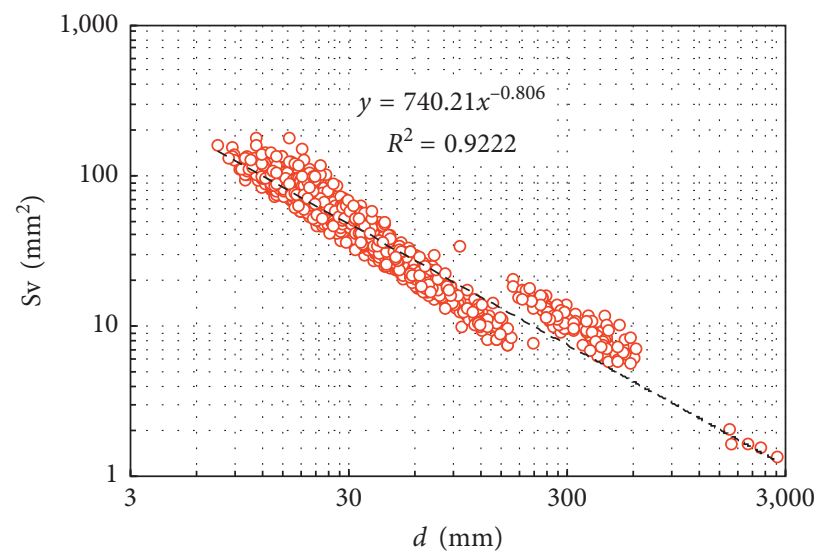

FIGURE 10: Relationship between specific surface area and particle size.
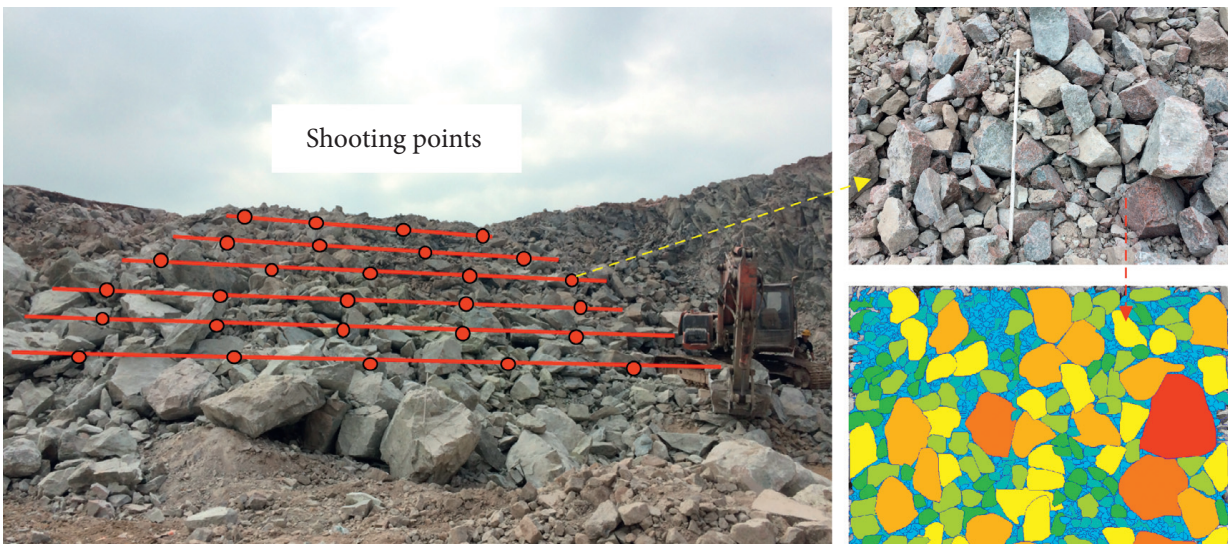

FIGURE 11: Image recognition method of fragment size distribution of muck pile.

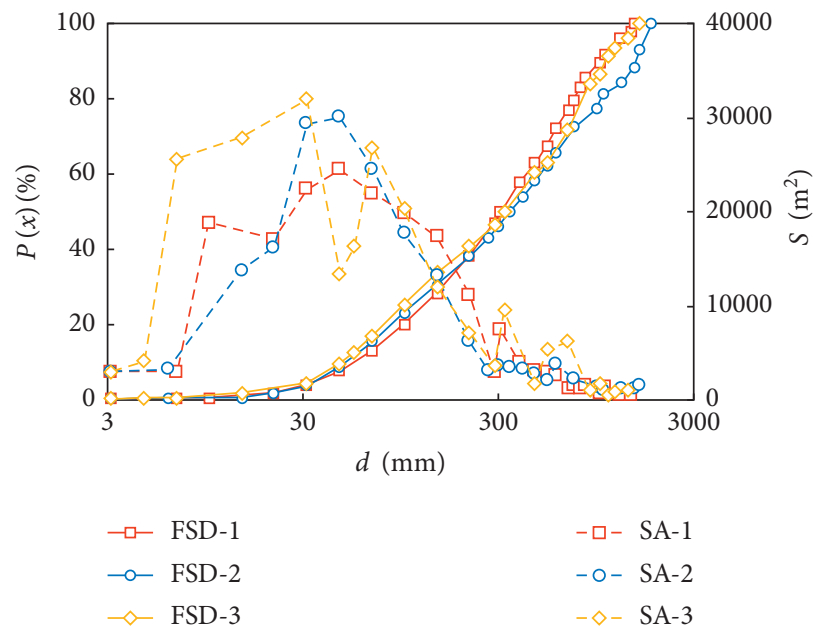

FIGURE 12: Fragment size distribution and surface area in each size range of three blasting tests.

fracture. According to the surface area in each size range from Figure 12, water-decked blasting will generate more small rock fragments and more new free surface areas. Based on (3), compared with normal blasting, more explosive energy is consumed for small rock fragments in waterdecked blasting test. It is noteworthy that, owing to the 
TABLe 6: Fragmentation energy in each blasting test.

\begin{tabular}{lccccc}
\hline Blast no. & $A / V\left(\mathrm{~m}^{2}\right)$ & $A_{F} / V\left(\mathrm{~m}^{2}\right)$ & $E_{\mathrm{QT}}(\mathrm{MJ})$ & $E_{F}(\mathrm{MJ})$ & $E_{F} / E_{\mathrm{QT}}(\%)$ \\
\hline 1 & 43.9 & 43.7 & 5399.8 & 98.2 & 1.82 \\
2 & 42.5 & 42.3 & 5399.8 & 99.6 & 1.85 \\
3 & 48.1 & 47.9 & 5399.8 & 114.7 & 2.12 \\
\hline
\end{tabular}
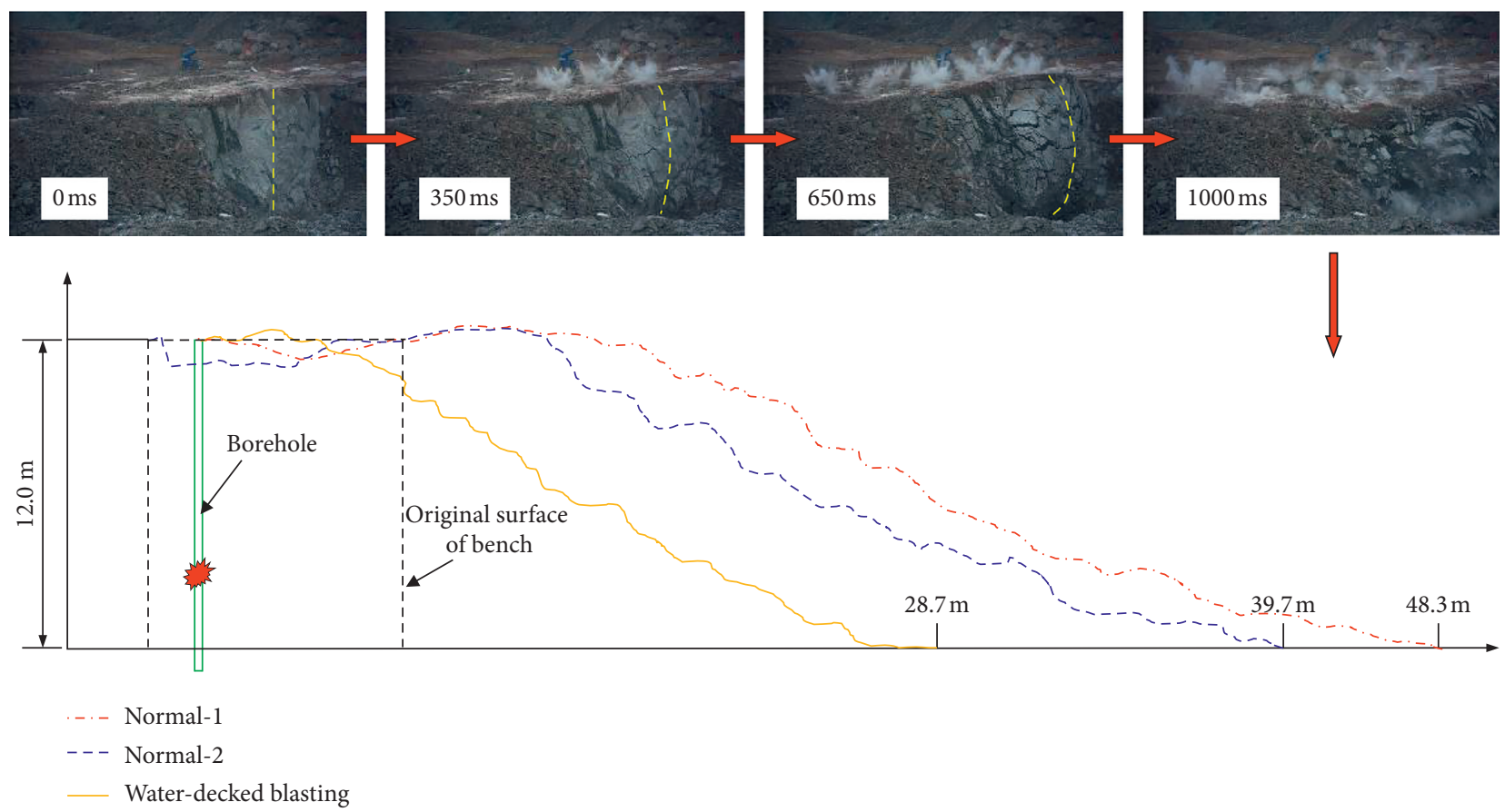

FIgURE 13: Throwing and accumulation of rock fragments in bench blasting.

limitations in the software's recognition accuracy and photograph quality, the minimum size of the rock fragments is $3.0 \mathrm{~mm}$ in the analysis.

4.2.3. Fragmentation Energy. The rock mass is relatively intact in the blasting zone. Because joints or cracks are not developed, the original surface $A_{I S}$ is the geometric surface of the blasting zone. Table 6 shows the fragmentation energy in each blasting test, where $A$ is the total surface area of rock fragments, $A_{F}$ is the new surface area created by blasting, and $E_{\mathrm{QT}}$ is the total energy of explosive. It is clear that the fragmentation energy in water-decked blasting is greater than that in normal blasting (approximately 10\% greater), and more energy is consumed for rock breaking in waterdecked blasting.

4.3. Shape of Muck Pile. In bench blasting, when macrocracks are connected with each other, rock fragments will be thrown forward to form a muck pile under the actions of the explosion gas and stress waves. Figure 13 shows the process of rock throwing captured using a high-speed camera and the muck pile shapes from three blasting tests. It appears that the movement of the rock fragments implies that the speed is lower at both ends of the bench, while it is higher at the middle of the bench. In water-decked blasting, the water bag prevents the cracks along the axis of the borehole from interpenetrating rapidly; therefore, the speed in the middle of the bench can be reduced. This can not only cause more explosive energy to be consumed in rock fragmentation but also reduce fly rocks efficiently. According to the shape of the muck pile, the throwing distance in water-decked blasting is smaller than that in normal blasting, i.e., $28.7 \mathrm{~m}$ compared with beyond $40 \mathrm{~m}$ in other methods, and fly rocks are well controlled.

\section{Discussion}

Herein, the effect of the water-decked charge pattern on fragmentation energy is discussed. Compared with normal blasting, the energy utilization efficiency is higher in waterdecked blasting, which implies smaller rock fragments. For mining, this can improve the efficiency of shoveling and loading as well as reduce the energy consumption of subsequent mechanical crushing. For excavation, water-decked blasting renders the size of rock fragments more uniform and reduces the ratio of boulders after blasting. Generally, water-decked blasting yields a more efficient production.

However, this does not imply that water-decked blasting is better than normal blasting in all situations. Because of the 
greater borehole pressure, water-decked blasting will produce more useless fines, and the range of cracked zone in the remaining rock mass will be greater, which will result in the difficulty of drilling. Meanwhile, water-decked blasting is more complicated, and it may delay the construction schedule. An appropriate blasting method should be selected according to actual requirements in engineering.

In this test, the diameter of the water bag was approximately $102 \mathrm{~mm}$, which was slightly smaller than the diameter of the borehole for placement; therefore, an air gap appeared between the water bag and the borehole wall. The shock wave will compress the air before compressing the water column, and the maximum borehole pressures of water-decked blasting and normal blasting can be calculated according to equations (9)-(12). It appears that the ratio of the maximum borehole pressure of the two blasts is approximately 1.66 when considering the air gap, while it is approximately 2.04 without the air gap. Although water-decked blasting is better for rock fragmentation, the negative effect of the air gap cannot be ignored. In engineering, a water bag of a suitable size should be selected to reduce the thickness of the air gap.

\section{Conclusion}

Herein, the effect of water-decked blasting on fragmentation energy was studied. By theory and numerical simulations, the maximum borehole pressure and damage distribution of two types of charge patterns were discussed. Three blasting tests were performed at a granite-based field, and the fragmentation energy of both water-decked blasting and normal blasting was measured. The conclusions are as follows:

(1) When the charge amount of each borehole was the same, the maximum borehole pressure of waterdecked blasting was much greater than that of normal blasting, which will strengthen the rock fragmentation.

(2) Numerical simulation demonstrated that waterdecked blasting was more advantageous for the transmission of explosive energy. In water-decked blasting, the damage level of rocks was higher and the damage distribution was more uniform, which resulted in smaller rock fragments.

(3) The fragmentation energy of three blasting tests were measured based on the specific surface area and fragment size distribution of granite; it showed that water-decked blasting produced smaller rock fragments, and the fragmentation energy was $10 \%$ greater than that in normal blasting.

(4) Water-decked blasting could reduce fly rocks efficiently and ensure the safety of rock excavation.

\section{Data Availability}

The data used to support the findings of this study are available from the corresponding author upon request.

\section{Conflicts of Interest}

The authors wish to confirm that no known conflicts of interest are associated with this publication and that no significant support has been received for this study that could have influenced its outcome.

\section{Acknowledgments}

This study was financially supported by the National Natural Science Fund Project of China (51779190) and the Hubei Province Technical Innovation Program (2017ACA102). The authors wish to express their gratitude to all supporters.

\section{References}

[1] H. Hu, W. Lu, P. Yan, M. Chen, and Q. Gao, "A vibrationisolating blast technique with shock-reflection device for dam foundation excavation in complicated geological conditions," Shock and Vibration, vol. 2018, Article ID 8029513, 11 pages, 2018.

[2] H. I. P. Galvez, "Analysis of the state of the art of blast-induced fragment conditioning," Minerals Engineering, vol. 24, no. 14, pp. 1638-1640, 2011.

[3] D. Tromans, "Mineral comminution: energy efficiency considerations," Minerals Engineering, vol. 21, no. 8, pp. 613-620, 2008.

[4] F. Ouchterlony, U. Nyberg, M. Olsson et al., "Where does the explosive energy in rock blasting rounds go?" Science and Technology of Energetic Materials, vol. 65, no. 2, pp. 54-63, 2004.

[5] E. Hamdi, J. D. Mouza, and J. A. Fleurisson, "Evaluation of the part of blasting energy used for rock mass fragmentation," Fragblast, vol. 5, no. 3, pp. 180-193, 2001.

[6] E. Hamdi, N. B. Romdhane, and J. D. Mouza, "Fragmentation energy in rock blasting," Geotechnical and Geological Engineering, vol. 26, no. 2, pp. 133-146, 2008.

[7] K. A. Offei and Doyle, Energy Efficiency in the Minerals Industry, Springer, Berlin, Germany, 2018.

[8] J. A. Sanchidrián, P. Segarra, and L. M. López, "Energy components in rock blasting," International Journal of Rock Mechanics and Mining Sciences, vol. 44, no. 1, pp. 130-147, 2007.

[9] X. Shi, J. Zhou, B. Wu, D. Huang, and W. Wei, "Support vector machines approach to mean particle size of rock fragmentation due to bench blasting prediction," Transactions of Nonferrous Metals Society of China, vol. 22, no. 2, pp. 432-441, 2012.

[10] J. Sudhakar, G. R. Adhikari, and R. N. Gupta, "Comparison of fragmentation measurements by photographic and image analysis techniques," Rock Mechanics and Rock Engineering, vol. 39, no. 2, pp. 159-168, 2006.

[11] U. Kuila and M. Prasad, "Specific surface area and pore-size distribution in clays and shales," Geophysical Prospecting, vol. 61, no. 2, pp. 341-362, 2013.

[12] I. Mehdipour and K. H. Khayat, "Effect of particle-size distribution and specific surface area of different binder systems on packing density and flow characteristics of cement paste," Cement and Concrete Composites, vol. 78, pp. 120-131, 2017.

[13] Y. Wang and J. Liu, "Calculation model and decoupling coefficient sensitivity study of periphery hole for eccentric decoupled charge in highway tunnels," Shock and Vibration, vol. 2018, Article ID 9734529, 11 pages, 2018. 
[14] M. Wang, X. Shi, J. Zhou, and X. Qiu, "Multi-planar detection optimization algorithm for the interval charging structure of large-diameter longhole blasting design based on rock fragmentation aspects," Engineering Optimization, vol. 50, no. 12, pp. 2177-2191, 2018.

[15] Z. Wang and Y. Li, "Numerical simulation on effects of radial water-decoupling coefficient in engineering blast," Rock and Soil Mechanics, vol. 26, no. 12, p. 1926, 2005.

[16] Z. Zhu, H. Xie, and B. Mohanty, "Numerical investigation of blasting-induced damage in cylindrical rocks," International Journal of Rock Mechanics and Mining Sciences, vol. 45, no. 2, pp. 111-121, 2008.

[17] H. Jang, D. Handel, Y. Ko, H. Yang, and M. James, "Effects of water deck on rock blasting performance," International Journal of Rock Mechanics and Mining Sciences, vol. 112, no. 1, pp. 77-83, 2018.

[18] F. V. Donze, J. Bouchez, and S. A. Magnier, "Modeling fractures in rock blasting," International Journal of Rock Mechanics and Mining Sciences, vol. 34, no. 8, pp. 1153-1163, 1997.

[19] D. Johansson and F. Ouchterlony, "Shock wave interactions in rock blasting: the use of short delays to improve fragmentation in model-scale," Rock Mechanics and Rock Engineering, vol. 46, no. 1, pp. 1-18, 2013.

[20] H. Ak, M. Iphar, M. Yavuz, and K. Adnan, "Evaluation of ground vibration effect of blasting operations in a magnesite mine," Soil Dynamics and Earthquake Engineering, vol. 29, no. 4, pp. 669-676, 2009.

[21] M. Monjezi, A. Bahrami, A. Y. Varjani, and R. S. Ahmad, "Prediction and controlling of flyrock in blasting operation using artificial neural network," Arabian Journal of Geosciences, vol. 4, no. 3-4, pp. 421-425, 2011.

[22] D. E. Grady and M. E. Kipp, "Continuum modelling of explosive fracture in oil shale," International Journal of Rock Mechanics and Mining Sciences \& Geomechanics Abstracts, vol. 17, no. 3, pp. 147-157, 1980.

[23] P. A. Persson, "The relationship between strain energy, rock damage, fragmentation, and throw in rock blasting," Fragblast, vol. 1, no. 1, pp. 99-110, 1997.

[24] Y. Zhang, Y. Lu, and H. Hao, "Analysis of fragment size and ejection velocity at high strain rate," International Journal of Mechanical Sciences, vol. 46, no. 1, pp. 27-34, 2004.

[25] L. Liu and P. D. Katsabanis, "Development of a continuum damage model for blasting analysis," International Journal of Rock Mechanics and Mining Sciences, vol. 34, no. 2, pp. 217-231, 1997.

[26] I. Onederra, M. J. Thurley, and A. Catalan, "Measuring blast fragmentation at Esperanza mine using high-resolution 3D laser scanning," Mining Technology, vol. 124, no. 1, pp. 34-36, 2015.

[27] G. Ke, L. Zhang, and Y. Xie, "Measurement of specific surface area of aggregate based on Image-Pro Plus," Concrete, vol. 9, no. 1, pp. 157-160, 2017.

[28] S. Esen, I. Onederra, and H. A. Bilgin, "Modelling the size of the crushed zone around a blasthole," International Journal of Rock Mechanics and Mining Sciences, vol. 40, no. 4, pp. 485-495, 2003.

[29] Q. Zong and D. Meng, "Influence of different kinds of hole charging structure on explosive energy transmission," Chinese Journal of Rock Mechanics and Engineering, vol. 22, no. 4, pp. 641-645, 2003.

[30] Q. Liu and P. D. Katsabanis, "A theoretical approach to the stress waves around a borehole and their effect on rock crushing," in Proceedings of the International Symposium on
Rock Fragmentation by Blasting, pp. 9-16, Vienna, Austria, July 1993.

[31] P. A. Persson, R. Holmberg, and J. Lee, Rock Blasting and Explosives Engineering, CRC Press, Boca Raton, FL, USA, 2003.

[32] W. Lu, Z. Leng, H. Hu, M. Chen, and G. Wang, "Experimental and numerical investigation of the effect of blast-generated free surfaces on blasting vibration," European Journal of Environmental and Civil Engineering, vol. 22, no. 11, pp. 1374-1398, 2018.

[33] S. Gheibie, H. Aghababaei, S. H. Hoseinie, and Y. Pourrahimian, "Modified kuz-ram fragmentation model and its use at the sungun copper mine," International Journal of Rock Mechanics and Mining Sciences, vol. 46, no. 6, pp. 967-973, 2009.

[34] H. Jang, I. Kitahara, Y. Kawamura et al., "Development of 3D rock fragmentation measurement system using photogrammetry," International Journal of Mining, Reclamation and Environment, vol. 34, no. 4, pp. 294-305, 2020. 